\title{
Does the cis/trans configuration of peptide bonds in bioactive tripeptides play a role in ACE-I enzyme inhibition?
}

This article was published in the following Dove Press journal:

Biologics:Targets and Therapy

II February 2014

Number of times this article has been viewed

\author{
Aino Siltari' \\ Riikka Viitanen ${ }^{2}$ \\ Sampo Kukkurainen² \\ Heikki Vapaatalo' \\ Jarkko Valjakka \\ 'Institute of Biomedicine, \\ Pharmacology, University of Helsinki, \\ Finland; ${ }^{2}$ BioMediTech, Institute of \\ Biomedical Technology, University of \\ Tampere, Finland
}

Background: The milk casein-derived bioactive tripeptides isoleucine-proline-proline (IPP) and valine-proline-proline (VPP) have been shown to prevent development of hypertension in animal models and to lower blood pressure in moderately hypertensive subjects in most but not all clinical trials. Inhibition of angiotensin-converting enzyme 1 (ACE-1) has been suggested as the explanation for these antihypertensive and beneficial vascular effects. Previously, human umbilical vein endothelial cells (HUVEC) have not been used to test ACE-1 inhibiting properties of casein derived tripeptides in vasculature.

Purpose: We focused on the cis/trans configurations of the peptide bonds in proline-containing tripeptides in order to discover whether the different structural properties of these peptides influence their activity in ACE-1 inhibition. We hypothesized that the configuration of prolinecontaining peptides plays a significant role in enzyme inhibition.

Methods: AutoDock 4.2 docking software was used to predict suitable peptide bond configurations of the tripeptides. Besides modeling studies, we completed ACE-1 activity measurements in vitro using HUVEC cultures.

Results: In HUVEC cells, both IPP and VPP inhibited ACE-1. Based on molecular docking studies, we propose that in ACE-1 inhibition IPP and VPP share a similar cis configuration between the first aliphatic (isoleucine or valine) and the second (proline) amino acid residues and more different configurations between two proline residues. In vivo experiments are needed to validate the significance of the present findings.

Keywords: ACE inhibition, Autodock modeling, Ile-Pro-Pro, Val-Pro-Pro, vascular function

\section{Introduction}

The milk casein-derived tripeptides isoleucine-proline-proline (IPP) and valineproline-proline (VPP), formed during fermentation or enzymatic hydrolysis, have been shown to have physiological effects not only on blood pressure-regulating systems in animal models ${ }^{1}$ and in humans, ${ }^{2}$ but also on other tissues such as eye and blood vessels. ${ }^{3,4}$ These tripeptides prevent development of hypertension in different animal models ${ }^{4-7}$ and lower blood pressure in mildly hypertensive humans. ${ }^{8-10}$ They also improve impaired endothelium-dependent vascular relaxation in hypertensive rats. ${ }^{2,11-13}$ Tripeptides inhibit angiotensin-converting enzyme 1 (ACE-1) in vitro; ${ }^{6,7,14}$ tripeptides also inhibit the activity of ACE- 1 measured in plasma ${ }^{15}$ and serum $^{16}$ after peptide feeding. ACE-1 is the main blood pressure-regulating enzyme in the renin-angiotensin system and is therefore a target for antihypertensive therapy. Tripeptides have also been studied with other blood pressure-affecting enzymes in addition to ACE- $1^{3}$, including prolyl oligopeptidase and arginase- $1 .{ }^{14,17}$
Correspondence: Jarkko Valjakka BioMediTech, Institute of Biomedical Technology, FI-330I 4 University of Tampere, Finland

Tel +358 3355 III

Fax +358 3364 I29।

Email jarkko.valjakka@uta.fi 
Interestingly, they preserve endothelial function in vitro ${ }^{11}$ and potentiate on bradykinin and angiotensin-(1-7) [Ang(1-7)] induced vasodilatation. ${ }^{18}$ Bradykinin and Ang-(1-7) are physiological vasodilators believed to have some interaction with each other via the ACE-2-Mas-receptor axis. ${ }^{19,20}$

In this study our interest is vascular endothelial ACE-1. We suggest that the antihypertensive effects of the peptides are somehow related to their configuration in ACE-1 inhibition. Some controversies in clinical studies and distinctions between our findings and a few others ${ }^{4,5,11-14}$ led us to suggest that the peptides could exist not only in various conformations but also different configurations in experimental studies, which would explain the varying findings in clinical studies. ${ }^{8-10}$ Differences in the geometrical forms of active site residues and substrates influence binding affinity and specificity of enzyme comprehensively; additionally, because all enzymes are composed of chiral amino acids residues, it is logical that enzyme inhibition depends on their inhibitor's geometric isomers. Normally, while D/L and $\mathrm{R} / \mathrm{S}$ stereoisomer configuration in the peptide inhibitors is discussed, ${ }^{21,22}$ cis/trans configuration isomers in the peptide chain (as shown in Figure 1) are usually neglected. All these suggestions may be relevant to the absorption of peptides that require selective transporters.

We concentrate herein on tripeptides - namely IPP and VPP - that consist of two prolines and one aliphatic residue. Proline residue has less conformational freedoms in proteins and peptide structures since its side chain is covalently bonded

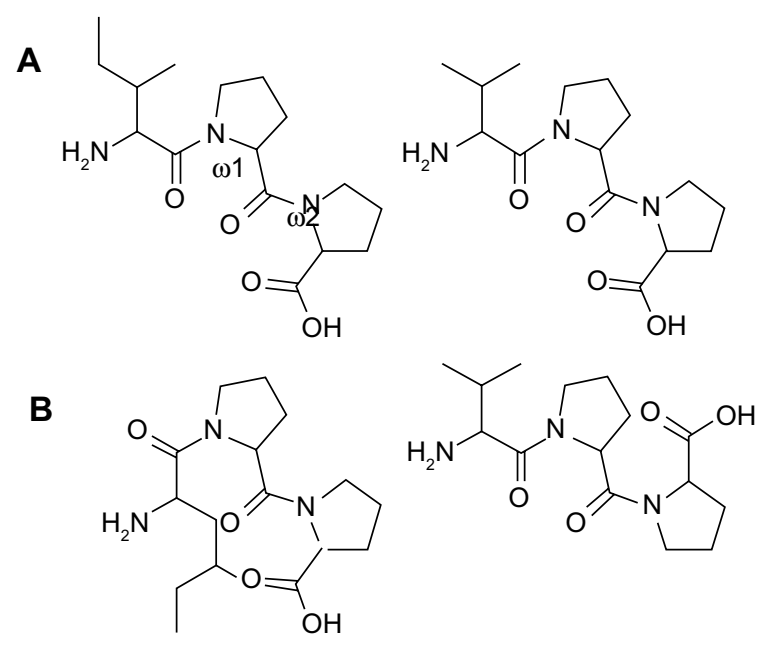

Figure I Different cis/trans configurations of the peptide bond.

Notes: (A) Peptide bonds values $(\omega \mathrm{I}$ and $\omega 2)$ in IPP and VPP are $180^{\circ}$ and they are both in trans configuration. (B) The first peptide bond $(\omega \mathrm{I})$ in IPP has $0^{\circ}$ and the second $(\omega 2)$ has $180^{\circ}$ values and they are in cis and trans configuration, respectively. The first peptide bond $(\omega \mathrm{I})$ in VPP has $180^{\circ}$ and the second $(\omega 2)$ has $0^{\circ}$ values and they are in trans and cis configuration, respectively.

Abbreviations: IPP, isoleucine-proline-proline; VPP, valine-proline-proline. to the main chain; there is thus the possibility of the proline peptide bond having a broader configuration distribution. The cis/trans isomers are with the same amino acid residue content, but in different peptide bond configurations. For most peptide bonds, the trans configuration is favored about 1,000 times more than the cis configuration. However, in cases where the peptide has a proline residue, the trans configuration is only about four times more dominant. ${ }^{23}$

Various three-dimensional (3D) structures of the ACE-1 enzyme are currently available in the Protein Data Bank (PDB; http://www.pdb.org), ${ }^{24}$ allowing for detailed knowledge to be obtained about the nature of the active sites and the interactions between inhibitors and enzymes. To elucidate the inhibition of ACE-1 by IPP and VPP tripeptides, we computationally docked the tripeptides in order to relate their configuration to the inhibition of ACE-1. AutoDock docking software (version 4.2; Scripps Research Institute, Jupiter, FL, USA) was used to predict suitable peptide chain configurations of the tripeptides. Here we would like to report the relationship between peptide bond cis/trans configuration and the inhibition of ACE-1.

\section{Materials and methods}

\section{Preparation of ACE-I enzyme and tripeptide structures for the docking procedure}

All molecular dockings were performed with the AutoDock 4.2 program package from AutoDock Tools. ${ }^{25}$ The 3D structure of the target molecules (enzyme) as well the ligands (tripeptides) must be known to begin the analysis. The PDB, as of March 2012, was queried for human ACE-1 enzyme structures. The total number was five and it consists of four structures with an inhibitor and only one without the inhibitor. To avoid binding bias, an important criterion was that the starting model was an X-ray structure without any ligand. The initial coordinates for the docking analyses were obtained from the ACE-1 enzyme EC 3.4.15.1 (PDB ID 108A), determined to $2.0 \AA$ resolution. ${ }^{26}$ Generally, a resolution of approximately $2 \AA$ provides an accurate structure, and accordingly, such a structure is suitable for docking. To obtain the initial coordinates for the tripeptides, they were constructed using DeepView - Swiss-PdbViewer (Swiss Institute of Bioinformatics, Lausanne, Switzerland). ${ }^{27}$ The tripeptide models solvated in TIP3P water and were subjected to conjugate gradient energy minimization calculations using the Amber ff99SB force field in NAMD 2.6 (University of Illinois, Urbana and Champaign, IL, USA); the first 4,000 steps were completed with protein atoms immobilized, 
followed by 8,000 steps with all atoms released. ${ }^{28-30}$ Only energy-minimized structures of IPP are shown in Figure 2.

\section{Autodock}

For the docking, ACE-1 enzyme and all tripeptide structures were dissolvated. Gasteiger charges and hydrogens for structures were added. The docking grid was prepared with a grid box created using the maximum points with spacing of $0.375 \AA$. In accordance with the Catalytic Site Atlas database, ${ }^{31}$ active site residues of ACE-1, His353, Glu384, Lys511, His513, Tyr520, and Tyr523 were selected as flexible residues. These side chains were permitted to be flexible over the docking calculations. All of the torsional bonds in each tripeptide were allowed to be free. Docking procedures included 10 independent runs. Module setting parameters were as follows: a population size of 150; a maximum number of 2.5 million energy evaluations; a maximum of 27,000 generations, a crossover rate of 0.8 ; and a number rate of 0.02 . Based on a root mean square deviation criterion of $1.0 \AA$, the docking results were clustered.

\section{Human umbilical vein endothelial cell (HUVEC) culture}

HUVEC cells are a commonly used cell line in cardiovascular research. ${ }^{32,33}$ Commercial HUVEC (Lonza Inc.,

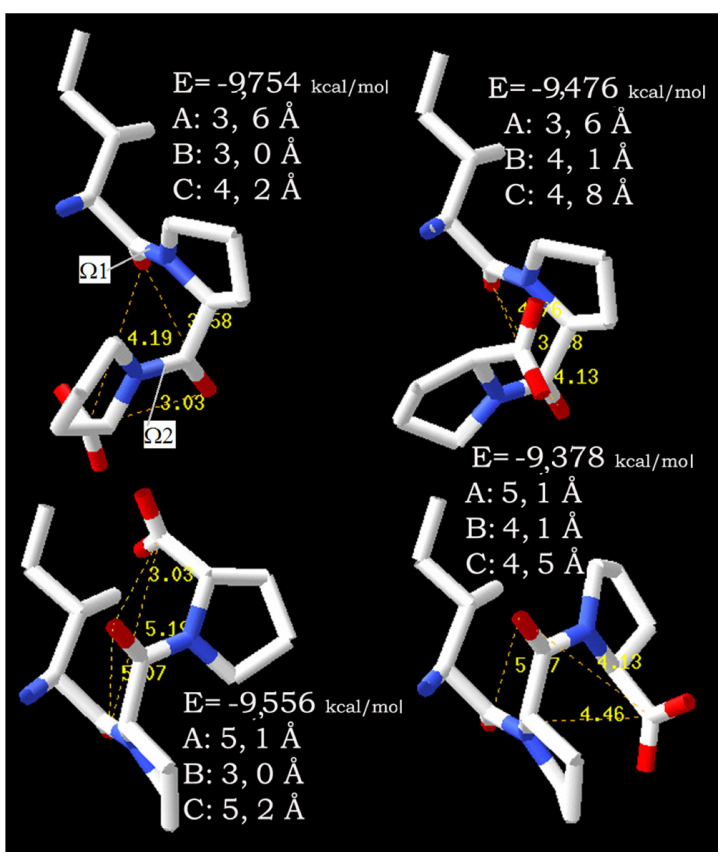

Figure 2 Different cis/trans configurations of IPP.

Notes: Different cis/trans configurations of the isoleucine-proline-proline are shown in global energy minimum structures. The shortest distances between carbonyl oxygens are provided. Blue color indicates nitrogen and red color oxygen atoms. Different peptide bond configurations of IPP are sorted by energy, from smallest to largest. Abbreviation: IPP, isoleucine-proline-proline.
Walkersville, MD, USA) were cultured in endothelial cell basal medium (Lonza) containing 10\% fetal bovine serum, $0.1 \%$ recombinant human epidermal growth factor, $0.1 \%$ gentamicin sulfate (GA-1000), 0.1\% hydrocortisone, and $0.4 \%$ bovine brain extract. Cells were cultivated at $37^{\circ} \mathrm{C}$ with $5 \% \mathrm{CO}_{2}$, and a fresh medium was provided every 1-2 days. Cells used in the experiments were from the passage 6 . At the end of the experiments, mycoplasma tests (MycoAlert Mycoplasma Detection Kit; Lonza Inc.) were performed to exclude possible infections of the cells. All mycoplasma tests were negative (data not shown).

\section{ACE-I activity assay}

ACE-1 activity was measured using the method devised by Santos et al. ${ }^{34}$ The assay was based on two reactions: in the first reaction, N-hippuryl-histidine-leucine (HHL) (Sigma-Aldrich, St Louis, MO, USA) was depredated into histidine-leucine (HL) (Sigma-Aldrich) by ACE-1, and in the second reaction HL and ortho-phthaldialdehyde (OPA) (Sigma-Aldrich) formed under the alkaline conditions of a fluorescent complex, which was measured at excitation/ emission $=365 / 495 \mathrm{~nm}$. The assay buffer contained $0.1 \mathrm{M}$ sodium borate and $0.4 \mathrm{M}$ sodium chloride $(\mathrm{pH} 8.3)$. HHL $(10 \mu \mathrm{M})$ and HL $(0.05-15 \mu \mathrm{M})$ were diluted in the assay buffer. Pure HL was used as the standard. OPA (2\%) was diluted in methanol. ACE-1 activity was measured from cell lysate using tripeptide (H-4632/H-4634; Bachem, Bubendorf, Switzerland) concentrations $0.1,1.0$, and $3.3 \mu \mathrm{M}$. Purity of tripeptides was $>98 \%$, but they were a mixture of cis/trans configurations. The reaction was stopped using acid after a 60 minute-long incubation and centrifuged at 3,000 rpm for 10 minutes. Fluorescence was measured using a fluorescence spectrophotometer (Varian Cary Eclipse; Agilent Technologies, Santa Clara, CA, USA) from the supernatant shortly after centrifugation. Captopril (1 nM) was used as a positive control for ACE-1 inhibition. ${ }^{35,36}$ All concentrations reported were the final concentrations in the reaction.

\section{Statistics}

The results from enzyme activity measurements are presented as mean \pm standard error of mean (SEM), ( $n=2-4$ each concentration from duplicate measurements). Statistical analyses were performed using GraphPad Prism software (version 4.02; GraphPad Software, Inc., La Jolla, CA, USA). Oneway analysis of variance (ANOVA) followed by Dunnett's multiple comparison test was used to compare the results. A difference was considered significant if $P<0.05$. 


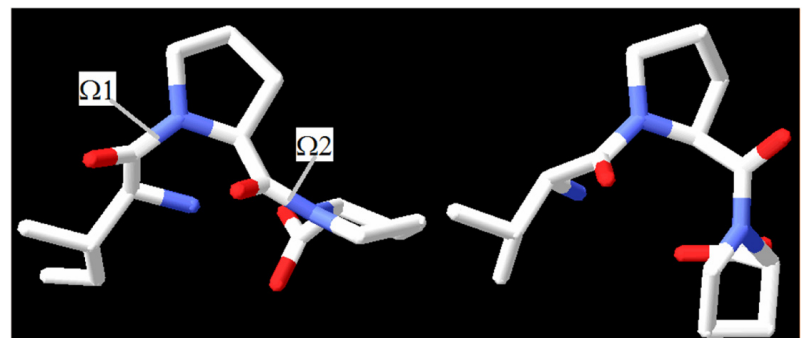

Figure 3 Geometric isomers and omega values IPP and VPP

Notes: Geometric isomers and omega values for IPP were $\omega \mid=-42$ and $\omega 2=-7$, respectively. Geometric isomers and omega values for VPP were $\omega \mathrm{I}=-99$ and $\omega 2=84$ for VPP, respectively. These values were as predicted in the angiotensinconverting enzyme $\mathrm{I}$.

Abbreviations: IPP, isoleucine-proline-proline; VPP, valine-proline-proline.

\section{Result and discussion}

\section{Computed geometric models}

Outside a certain enzyme, the tripeptide whirls freely in aqueous solution through rotation of the $\mathrm{N}-\mathrm{C}_{\alpha}($ phi, $\phi)$ and $\mathrm{C}_{\alpha}-\mathrm{C}^{\prime}(\mathrm{psi}, \psi)$ bonds. Since freedom of rotation in the active site becomes restricted through formation of the inhibitorenzyme complex, these rotations to a large extent become frozen. Peptide inhibitors generally bind enzymes in a single well-defined structure and appropriate interactions. All isomers -including cis/trans configuration isomers get to the energy equilibrium ratio that is dependent on the conditions. Usually, this local structure contains the correct orientations for interactions and is nearly a global minimum energy structure. The interconversion between isomers is a slow process because structure rearrangement in inhibitors requires energy-owing peptide bonds to break, ${ }^{37,38}$ as well as new organizing of enzyme active site residues. According to the Autodock predictions, the primary structures of IPP and VPP are quite different in the active site of the ACE-1 enzyme. Their different geometry orientations of carbonyl oxygens are shown in Figure 3. Carbonyl oxygens are the most potent hydrogen bond acceptors in the common peptide bonds. IPP and VPP share a similar cis configuration at the omega bond $(\omega 1)$ between the first aliphatic (isoleucine or valine) and the second (proline) amino acid residues and other different configurations between two proline residues. This indicates that particular attention should be paid to this point in the future.

\section{Experimental inhibition models}

While in the X-Pro type main chain the peptide bond is more likely to be in the cis configuration than in the other type, the actual percentage amount of distribution between cis/trans configurations can vary. Additionally, clinical studies and in vitro experiments with somewhat contradictory results raise the possibility that different production procedures might finalize compounds of varying geometric isomers. ${ }^{39-41}$ Therefore, we suggest that the bacterial fermentation or enzymatic treatment of milk casein might produce divergent tripeptides which have different structural distribution (eg, cis/trans peptide configuration). The main point is that configuration modifications clearly need more energy than conformation changes..$^{38} \mathrm{~A}$ previous study by Counterman and Clemmer ${ }^{42}$ shows that in tryptic-digested peptides less than ten amino acid residues have different cis/trans configurations; this study supports our hypothesis.

It has been evident for some time that enzymatic breakdown or bacterial fermentation produces small peptides from milk casein; peptides possess many biological activities ${ }^{43}$ and are marketed as functional foods in some countries (eg, Japan). We used IPP and VPP for inhibition of ACE-1 dose-dependently (Figure 4), and half maximal inhibitory
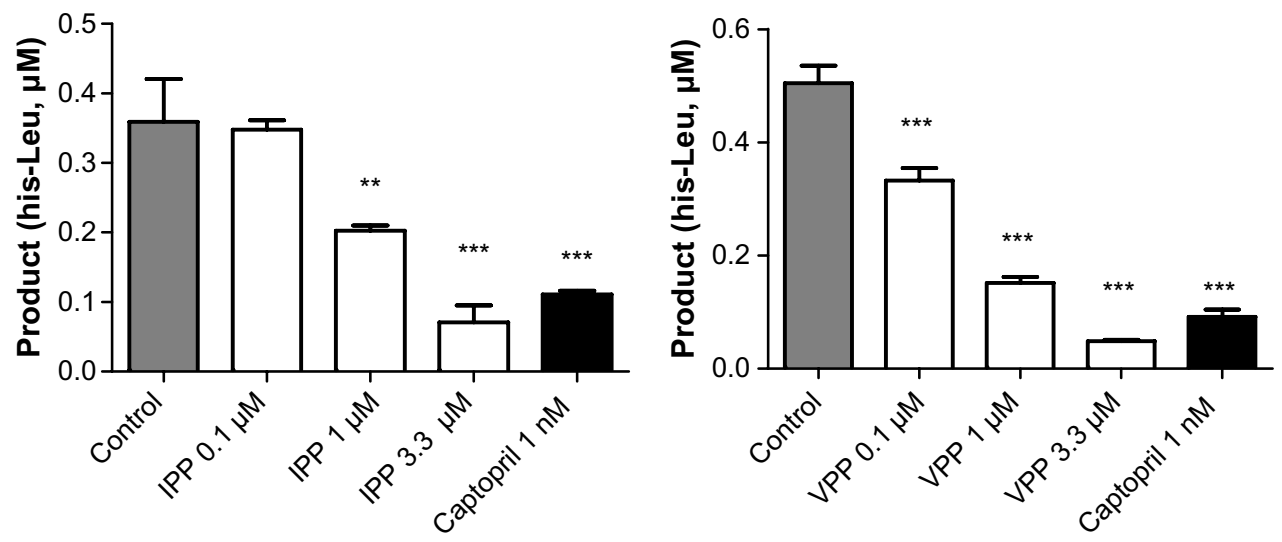

Figure 4 Angiotensin-converting enzyme I activity from HUVEC lysate.

Notes: Angiotensin-converting enzyme I activity from HUVEC lysate incubated for 60 minutes with/without IPP or VPP peptides. Captopril was used as a reference inhibitor. Mean \pm SEM, $n=2-4$, from duplicate measurements. $* * P<0.01$; $* * * P<0.001$ versus control.

Abbreviations: HUVEC, human umbilical vein endothelial cells; IPP, isoleucine-proline-proline; VPP, valine-proline-proline; SEM, standard error of mean. 


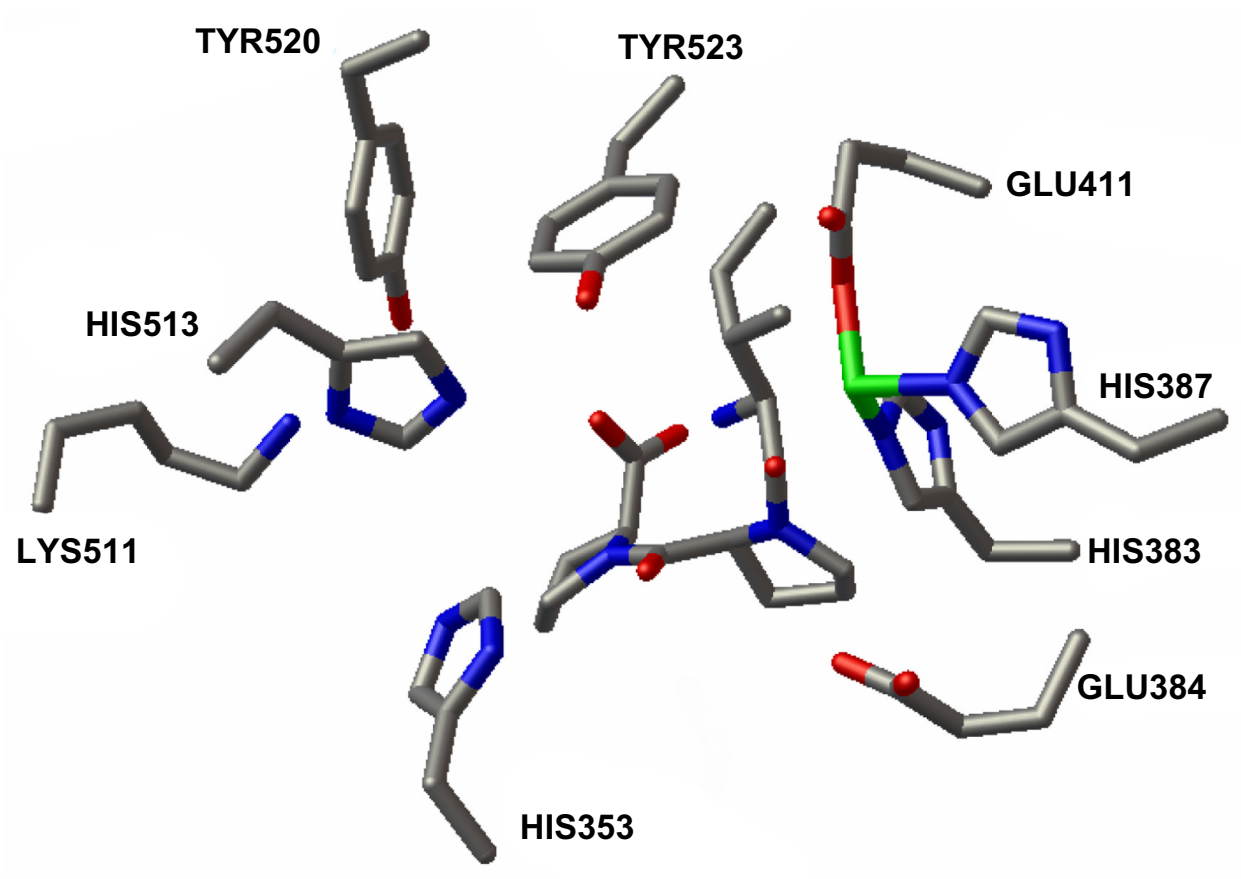

Figure 5 Tripeptide IPP in active site of ACE-I.

Notes: Tripeptide IPP with omega values of $\omega \mathrm{I}=-42$ and $\omega 2=-7$ in active site of ACE-I. Autodock flexible residues are labeled, as are zinc (green) and its two histidine $(383,387)$ and glutamine (384) ligand residues.

Abbreviations: IPP, isoleucine-proline-proline; ACE-I, angiotensin-converting enzyme I.

concentration $\left(\mathrm{IC}_{50}\right)$ for IPP and VPP were $1.89 \pm 0.28 \mu \mathrm{M}$ and $0.48 \pm 0.38 \mu \mathrm{M}$, respectively. The highest IPP and VPP concentration applied $(3.3 \mu \mathrm{M})$ induced similar ACE-1 inhibition to captopril $(1 \mathrm{nM})$. These results are compatible with our own previous results and those of another study by Foltz et al. ${ }^{44}$ It was also proved that there is a direct link between dipeptide stability and ACE-1 inhibition, as modeled by the quantitative structure-activity relationship method..$^{45}$

We have previously tested tripeptides produced by two different manufacturing processes using a hypertensive rat model. Unfortunately, the peptide powders were only half from bacterial fermentation and split by proline specific endoprotease. Thus the real significance of processing procedures remained unsolved. ${ }^{46}$ Molecular structure aspects are not the only important factor in the evaluation of inhibition of geometric isomers of tripeptides. Pharmacokinetics may also be affected; the absorption, metabolism, and clearance of the peptides may be modified by isomerization. Thus, the individual isomers of the tripeptide may be metabolized at different rates and transformed to another isomer entity. Furthermore, to become a functional food product, it may be necessary to both improve the structural properties of a peptide-like product and to search for optimal additives for a special peptide; improvements in peptide solubility, chemical stability in biological matrices, or metabolic stability will be the next subject of experiments.

\section{Conclusion}

Our hypothesis that cis/trans configuration variability in peptide bonding may play a significant role in enzyme inhibition was tested by computing molecular modeling and by experimental work with two casein-derived tripeptides (IPP, VPP). Based on our Autodock data, we conclude that the cis configuration of the first peptide bond on the IPP and VPP tripeptides is a more potent geometric form for ACE-1 inhibition. Individual configuration of the peptides produced in different ways should be clarified before drawing strict conclusions from in vitro and in vivo experiments. Small peptides may, under appropriate conditions, fold to different geometric forms; therefore, it would be valuable to control the main chain geometry during the peptide manufacturing process. Additionally, the interactions of cis/trans configurations can in general be assumed to be geometrically driven at the active site. This means that one configuration binds with higher affinity than the other upon interacting with an enzyme (Figure 5).

\section{Acknowledgments}

This study was financially supported by Päivikki and Sakari Sohlberg Foundation (Siltari), the Competitive Research Funding of Tampere University Hospital Grant 9K144 (Valjakka) and Finska Läkaresällskapet Finland (Vapaatalo). 


\section{Disclosure}

The authors report no conflicts of interest in this work.

\section{References}

1. Jäkälä P, Vapaatalo H. Antihypertensive peptides from milk proteins. Pharmaceuticals. 2010;3(1):251-272.

2. Turpeinen AM, Järvenpää $\mathrm{S}$, Kautiainen $H$, Korpela R, Vapaatalo H. Antihypertensive effects of bioactive tripeptides - a random effects meta-analysis. Ann Med. 2013;45(1):51-56.

3. Luhtala S, Vaajanen A, Oksala O, Valjakka J, Vapaatalo H. Activities of angiotensin-converting enzymes 1 (ACE1) and 2 (ACE2) and inhibition by bioactive peptides in porcine ocular tissues. J Ocul Pharmacol Ther. 2009;25(1):23-28.

4. Sipola M, Finckenberg P, Santisteban J, Korpela R, Vapaatalo H, Nurminen ML. Long-term intake of milk peptide attenuates development of hypertension in spontaneously hypertensive rats. $J$ Physiol Pharmacol. 2001;52(4 Pt2):745-754.

5. Jäkälä P, Hakala A, Turpeinen AM, Korpela R, Vapaatalo H. Caseinderived bioactive tripeptides Ile-Pro-Pro and Val-Pro-Pro attenuate the development of hypertension and improve endothelial function in salt-loaded Goto-Kakizaki rats. J Funct Foods. 2009;1(4):366-374.

6. Nakamura Y, Yamamoto N, Sakai K, Okubo A, Yamazaki S, Takano T. Purification and characterization of angiotensin I-converting enzyme inhibitors from sour milk. J Dairy Sci. 1995;78(4):777-783.

7. Nakamura Y, Yamamoto N, Sakai K, Takano T. Antihypertensive effect of sour milk and peptides isolated from it that are inhibitors of angiotensin I-converting enzyme. J Dairy Sci. 1995;78(6):1253-1257.

8. Xu JY, Qin LQ, Wang PY, Li W, Chang C. Effects of milk tripeptides on blood pressure: a meta-analysis of randomized controlled trials. Nutrition. 2008;24(10):933-940.

9. Cicero AFG, Gerocarni B, Laghi L, Borghi C. Blood pressure lowering effects of lactotripeptides assumed as functional food: a meta-analysis of current available clinical trials. J Hum Hypertens. 2011;25(7):425-436.

10. Turpeinen AM, Järvenpää S, Kautiainen H, Korpela R, Vapaatalo H. Antihypertensive effects of bioactive tripeptides - a random effects meta-analysis. Ann Med. 2013;45(1):51-56.

11. Jäkälä P, Jauhiainen T, Korpela R, Vapaatalo H. Milk protein-derived bioactive tripeptides Ile-Pro-Pro and Val-Pro-Pro protect endothelial function in vitro in hypertensive rats. J Funct Foods. 2009;1(3): 266-273.

12. Jauhiainen T, Pilvi T, Cheng ZJ, et al. Milk products containing bioactive tripeptides have an antihypertensive effect in double transgenic rats (dTGR) harbouring human renin and human angiotensinogen genes. J Nutr Metab. 2010;(2010);Article ID287030, 6 pages.

13. Sipola M, Finckenberg P, Korpela R, Vapaatalo H, Nurminen ML. Effect on long-term intake of milk products on blood pressure in hypertensive rats. J Dairy Res. 2002;69(1):103-111.

14. Lehtinen R, Jauhiainen T, Kankuri E, et al. Effects of milk casein-derived tripeptides Ile-Pro-Pro, Val-Pro-Pro, and Leu-Pro-Pro on enzymes processing vasoactive precursors in vitro. Arzneimittelforschung. 2010;60(4):182-185.

15. Jäkälä P, Pere E, Lehtinen R, Turpeinen A, Korpela R, Vapaatalo H. Cardiovascular activity of milk-casein-derived tripeptides and plant sterols in spontaneously hypertensive rats. J Phys Pharm. 2009;60(4): $11-20$.

16. Jauhiainen T, Collin M, Narva M, et al. Effect of long-term intake of milk peptides and minerals on blood pressure and arterial function in spontaneously hypertensive rats. Milk Sci Int. 2005;60(4):358-363.

17. Siltari A, Kivimäki AS, Ehlers PI, Korpela R, Vapaatalo H. Effects of milk casein derived tripeptides on endothelial enzymes in vitro; a study with synthetic tripeptides. Arzneimittelforschung. 2012;62(10):477-481.

18. Ehlers PI, Nurmi L, Turpeinen AM, Korpela R, Vapaatalo H. Casein-derived tripeptide Ile-Pro-Pro improves angiotensin-(1-7)and bradykinin-induced rat mesenteric artery relaxation. Life Sci. 2011:88(5-6);206-211.
19. Fernandes L, Fortes ZB, Nigro D, Tostes RCA, Santos RAS, Catelli De Carvalho MH. Potentiation of bradykinin by angiotensin-(1-7) on arterioles of spontaneously hypertensive rats studied in vivo. Hypertension. 2001;37(2 Pt 2):703-709.

20. Ueda S, Masumori-Meamoto S, Wada A, Ishii M, Brosnihan IB, Umemura S. Angiotensin(1-7) potentiates bradykinin-induced vasodilatation in man. J Hypertens. 2001;19(11):2001-2009.

21. Espín JC, García-Ruiz PA, Tudela J, García-Cánovas F. Study of stereospecificity in mushroom tyrosinase. Biochem J. 1998;331(Pt 2): 547-551.

22. Qu N, Ignatenko NA, Yamauchi P, et al. Inhibition of human ornithine decarboxylase activity by enantiomers of difluoromethylornithine. Biochem J. 2003;375(Pt 2):465-470.

23. London RE, Matwiyoff NA, Stewart JM, Cann JR. ${ }^{13}$ C nuclear magnetic resonance study of the cis-trans isomerism in X-Pro-Pro tripeptides. Biochemistry. 1978;17(12):2277-2283.

24. Berman HM, Westbrook J, Feng F, et al. The Protein Data Bank. Nucleic Acids Res. 2000;28(1):235-242.

25. Morris GM, Huey R, Lindstrom W, et al. Autodock4 and AutoDockTools4: automated docking with selective receptor flexiblity. J Comput Chem. 2009;30(16):2785-2791

26. Natesh R, Schwager SL, Sturrock ED, Acharya KR. Crystal structure of the human angiotensin-converting enzyme-lisinopril complex. Nature. 2003;421(6922):551-554.

27. Guex N, Peitsch MC. SWISS-MODEL and the Swiss-PdbViewer: An environment for comparative protein modeling. Electrophoresis. 1997; 18(15):2714-2723.

28. Phillips JC, Braun R, Wang W, et al. Scalable molecular dynamics with NAMD. J Comput Chem. 2005;26(16):1781-1802.

29. Hornak V, Abel R, Okur A, Strockbine B, Roitberg A, Simmerling C. Comparision of multiple amber force fields and development of improved protein backbone parameters. Proteins. 2006;65(3):712-725.

30. Wang J, Wolf RM, Caldwell JW, Kollman PA, Case DA. Development and testing of a general amber force field. J Comput Chem. 2004;25(9): $1157-1174$

31. Porter CT, Bartlett GJ, Thornton JM. The Catalytic Site Atlas: a resource of catalytic sites and residues identified in enzymes using structural data. Nucl Acids Res. 2004;32(Database issue):D129-D133.

32. Siow RC. Culture of human endothelial cells from umbilical veins. Methods Mol Biol. 2012;806:265-274.

33. Marin V, Kaplanski G, Gres S, Farnarier C, Bongrand P. Endothelial cell culture: protocol to obtain and cultivate human umbilical endothelial cells. J Immunol Methods. 2001;254(1-2):183-190.

34. Santos RA, Krieger EM, Greene LJ. An improved fluorometric assay of rat serum and plasma converting enzyme. Hypertension. 1985;7(2):244-252.

35. Rubin B, Antonaccio MJ, Goldberg ME, et al. Chronic antihypertensive effects of captopril (SQ 14,225), an orally active angiotensin I-converting enzyme inhibitor, in conscious 2-kidney renal hypertensive rats. Eur J Pharmacol. 1978;51(4):377-388.

36. Vollmer RR, Boccagno JA, Steinbacher TE, Horovitz ZP, Murthy VS. Antihypertensive effects of captopril (SQ 14,225), an orally active inhibitor of angiotensin I-converting enzyme in conscious two kidney perinephritic hypertensive dogs. J Pharmacol Exp Ther. 1981;216(2):225-231.

37. Mutter M, Wöhr T, Gioria S, Keller M. Pseudo-prolines: Induction of cis/trans-conformational interconversion by decreased transition state barriers. Biopolymers. 1999;51(2):121-128.

38. Schmid FX, Grafl R, Wrba, Beintema JJ. Role of proline peptide bond isomerization in unfolding and refolding of ribonuclease. Proc Natl Acad Sci U SA. 1986;83(4):872-876.

39. Engberink MF, Schouten EG, Kok FJ, van Mierlo LA, Brouwer IA, Geleijnse JM. Lactotripeptides show no effect on human blood pressure. Result on double-blinded randomiced controlled trial. Hypertension. 2008;51(2):399-405.

40. Van der Zander K, Bots ML, Bak AA, Koning MM, de Leeuw PW. Enzymatically hydrolyzed lactotripeptides do not lower blood pressure in mildly hypertensive subjects. Amer J Clin Nutr. 2008;88(6):1697-1702. 
41. Wuerzner G, Peyrard S, Blanchard A, Lalanne F, Azizi M. The lactotripeptides isoleucine-proline-proline and valine-prolineproline do not inhibit the $\mathrm{N}$-terminal or C-terminal angiotensin converting enzyme active sites in humans. J Hypertens. 2009;27(7): 1404-1409.

42. Countermann A, Clemmer DE. Cis-Trans signatures of prolinecontaining tryptic peptides in the gas phase. Anal Chem. 2002;74(9): 1946-1951.

43. Korhonen H. Milk-derived bioactive peptides: From science to applications. J Funct Foods. 2009;1(2):177-187.
44. Foltz M, van Buren L, Klaffke W, Duchateau GS. Modeling of the relationship between dipeptide structure and dipeptide stability, permeability, and ACE inhibition activity. J Food Sci. 2009;74(7): $\mathrm{H} 243-\mathrm{H} 251$.

45. Meyer RF, Essenburg AD, Smith RD, Kaplan HR. Angiotensin converting enzyme inhibitors: modification of a tripeptide analogue. J Med Chem. 1982;25(8):996-999.

46. Jäkälä P, Turpeinen AM, Rajakari K, Korpela R, Vapaatalo H. Biological effects of casein-derived tripeptides powders are not affected by fermentation process. Int Dairy J. 2010;20(5):366-370.

\section{Publish your work in this journal}

Biologics: Targets \& Therapy is an international, peer-reviewed journal focusing on the patho-physiological rationale for and clinical application of Biologic agents in the management of autoimmune diseases, cancers or other pathologies where a molecular target can be identified. This journal is indexed on PubMed Central, CAS, EMBase, Scopus

\section{Dovepress}

and the Elsevier Bibliographic databases. The manuscript management system is completely online and includes a very quick and fair peerreview system, which is all easy to use. Visit http://www.dovepress. com/testimonials.php to read real quotes from published authors. 